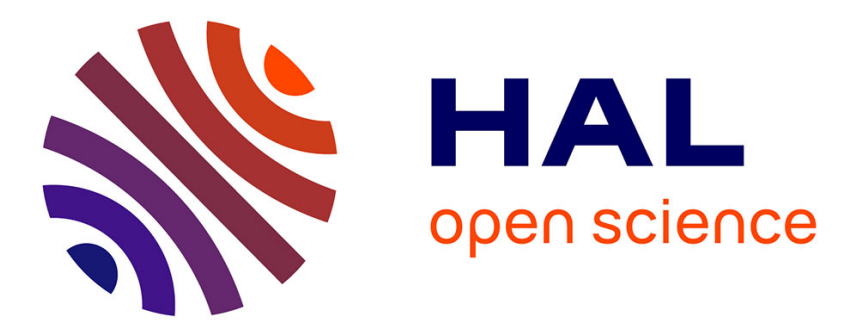

\title{
Freeze-casting for PLGA/carbonated apatite composite scaffolds: structure and properties
}

\author{
M. Schardosim, Jérémy Soulié, Dominique Poquillon, Sophie Cazalbou, \\ Benjamin Duployer, Christophe Tenailleau, Christian Rey, R. Hübler, \\ Christèle Combes
}

\section{To cite this version:}

M. Schardosim, Jérémy Soulié, Dominique Poquillon, Sophie Cazalbou, Benjamin Duployer, et al.. Freeze-casting for PLGA/carbonated apatite composite scaffolds: structure and properties. Materials Science and Engineering: C, 2017, vol. 77, pp.731-738. 10.1016/j.msec.2017.03.302 . hal-01623713

\section{HAL Id: hal-01623713 https://hal.science/hal-01623713}

Submitted on 25 Oct 2017

HAL is a multi-disciplinary open access archive for the deposit and dissemination of scientific research documents, whether they are published or not. The documents may come from teaching and research institutions in France or abroad, or from public or private research centers.
L'archive ouverte pluridisciplinaire HAL, est destinée au dépôt et à la diffusion de documents scientifiques de niveau recherche, publiés ou non, émanant des établissements d'enseignement et de recherche français ou étrangers, des laboratoires publics ou privés. 


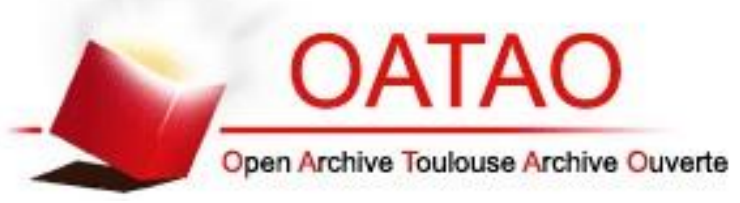

\section{Open Archive TOULOUSE Archive Ouverte (OATAO)}

OATAO is an open access repository that collects the work of Toulouse researchers and makes it freely available over the web where possible.

This is an author-deposited version published in : http://oatao.univ-toulouse.fr/ Eprints ID : 18212

To link to this article : DOI: 10.1016/j.msec.2017.03.302

URL : http://dx.doi.org/10.1016/j.msec.2017.03.302

To cite this version : Schardosim, M. and Soulié, Jérémy and Poquillon, Dominique and Cazalbou, Sophie and Duployer, Benjamin and Tenailleau, Christophe and Rey, Christian and Hübler, R. and Combes, Christèle Freeze-casting for PLGA/carbonated apatite composite scaffolds: structure and properties. (2017) Materials Science and Engineering C, vol. 77. pp.731-738. ISSN 0928-4931

Any correspondence concerning this service should be sent to the repository administrator: staff-oatao@ listes-diff.inp-toulouse.fr 


\title{
Freeze-casting for PLGA/carbonated apatite composite scaffolds: Structure and properties
}

\author{
M. Schardosim ${ }^{\text {a,b }}$, J. Soulié a,*, D. Poquillon a , S. Cazalbou ${ }^{\text {c }}$, B. Duployer ${ }^{\text {d }}$, C. Tenailleau ${ }^{\text {d }}$, C. Rey ${ }^{\text {a }}$, \\ R. Hübler ${ }^{\mathrm{b}}, \mathrm{C}$. Combes ${ }^{\mathrm{a}}$ \\ a CIRIMAT, Université de Toulouse, CNRS, INPT, UPS, ENSIACET, 4 allée Emile Monso, CS 44362, 31030 Toulouse cedex 4, France \\ b PUCRS, GEPSI-LMN, Porto Alegre, Brazil \\ c CIRIMAT, Université de Toulouse, CNRS, INPT, UPS, Université Paul Sabatier, Faculté de Pharmacie, 35 Chemin des Maraichers, 31062 Toulouse cedex 9, France \\ d CIRIMAT, Université de Toulouse, CNRS, INPT, UPS, Université Toulouse 3 Paul Sabatier, Bât. CIRIMAT, 118, Route de Narbonne, 31062 Toulouse cedex 9, France
}

Keywords:

Porous scaffolds

Composite

PLGA

Carbonated apatite

Bone engineering

\begin{abstract}
A B S T R A C T
This paper focuses on the fabrication of three-dimensional porous PLGA-biomimetic carbonated apatite composite scaffolds by freeze-casting and using dimethyl carbonate as a solvent. Several charge/polymer ratios were tested in order to finely understand the influence of the filler rate on the scaffold porosity and mechanical and degradation properties using complementary characterization techniques (SEM, mercury porosimetry and $\mathrm{X}$-ray microtomography). It was demonstrated that the apatite ratio within the composite scaffold has a strong influence in terms of architecture, material cohesion, mechanical properties and in vitro degradation properties. An optimum biomimetic apatite ratio was reached to combine good mechanical properties (higher rigidity) and material cohesion. In vitro degradation studies showed that higher apatite filler rates limited PLGA degradation and enhanced the hydrophilicity of the scaffolds which is expected to improve the biological properties of the scaffolds in addition to the bioactivity related to the presence of the apatite analogous to bone mineral.
\end{abstract}

\section{Introduction}

Bone defects resulting from disease or trauma may require the use of grafts to achieve bone regeneration. Although autologous graft [1] is considered as the gold standard, it presents some disadvantages related to the limited amount of tissue available, its quality and the need for two surgeries for patients [2,3]; these limitations led to the use of synthetic substitutes. During the last decade, the aim of bone tissue engineering has been to develop biodegradable and, if possible, bioactive materials. Ideally, biomaterials for bone regeneration should: i) demonstrate osteoconductivity to promote cell adhesion and differentiation, ii) stimulate new bone formation through cell differentiation and proliferation, iii) exhibit high porosity (pore size and total porosity) in order to support cell colonization and angiogenesis [4] and iv) maintain adequate mechanical strength until new bone formation is completed $[5,6]$.

Non-stoichiometric nanocrystalline calcium phosphate apatites $[7,8]$ mainly fit the two first criteria, due to their biomimetic characteristics (structural and chemical similarity with the mineral phase of bone) supporting their high bioactivity. Different processes (hard template [9], ice-templating [10]) can lead to porous calcium phosphate ceramics but

* Corresponding author at: CIRIMAT - ENSIACET, 4 allée Emile Monso, CS 44362, 31030 Toulouse cedex 4, France.

E-mail address: jeremy.soulie@ensiacet.fr (J. Soulié). mechanical cohesion is only obtained after a sintering step at high temperature. Unfortunately, these ceramics exhibit high fragility and low elasticity $[11,12]$. Moreover, as temperature tends to improve the crystallinity of calcium phosphate phases, thermal treatment decreases the reactivity/degradability of these materials [8] and then their biological properties [13]. One way to overcome this problem is the use of polymer/calcium phosphate composites. This association has been studied for several polymer matrices, involving natural (collagen, chitosan, gelatin) or synthetic polymers (polyesters, PMMA) [14,15]. Biodegradable synthetic polymers present good processability, high reproducibility and lower risk of contamination in comparison to natural polymers [16]. Among them, poly(D,L-lactic-co-glycolic acid) (PLGA) has been increasingly applied as a tissue engineering material due to its excellent biocompatibility and the possibility of controlling degradation time and mechanical properties by varying the copolymer composition [17]. Combination of the characteristics of PLGA and apatite allows production of scaffolds with suitable mechanical strength [18] and improvement of the degradation performance of such polyester-based materials through the influence of inorganic fillers in the polyester hydrolysis reaction $[19,20]$.

The control of porosity in such composites is a key parameter and different processes have been implemented: electrospinning with pore size and shape difficult to control in fiber assembly [18], hard template methods through the addition of porogenic agents [21], use of emulsions (soft template) in which removal of the oil phase is difficult 
[22] and freeze-casting methods, also called temperature-induced phase separation (TIPS), in which the crystals of frozen solvent are the template for the porosity before being sublimated.

This paper will focus on the fabrication of three-dimensional porous composite scaffolds of PLGA-carbonated apatite by TIPS. Contrary to previous studies [23], the solvent used in the process, dimethyl carbonate (DMC), is not carcinogenic or mutagenic $[24,25]$ and due to its crystallization properties can lead to pores with higher diameters [26]. As the size and structure of apatite particles can be controlled by the method of synthesis, several charge/polymer ratios will be tested in order to finely understand the influence of the filler rate on the scaffold porosity and surface features using complementary microstructural characterization techniques (scanning electron microscopy, mercury porosimetry and X-ray microtomography). Finally, this study aspires to correlate these observations with two major properties for bone substitute materials: mechanical and degradation properties.

\section{Materials and methods}

\subsection{Synthesis of nanocrystalline carbonated apatite}

Nanocrystalline carbonated apatite analogous to bone mineral was prepared by double decomposition between calcium salt and phosphate salt solutions. Briefly, the two solutions were prepared as follows. Solution A: calcium nitrate $\mathrm{Ca}\left(\mathrm{NO}_{3}\right)_{2}, 4 \mathrm{H}_{2} \mathrm{O}: 0.3 \mathrm{M}$ in $1500 \mathrm{~mL}$ of distilled water and solution $\mathrm{B}$ : diammonium hydrogenphosphate $\left(\mathrm{NH}_{4}\right)_{2} \mathrm{HPO}_{4}$ : $0.5 \mathrm{M}$ and sodium carbonate $\mathrm{NaHCO}_{3}: 0.7 \mathrm{M}$ in $3000 \mathrm{~mL}$ of distilled water. Solution A was rapidly poured into solution B at room temperature and under stirring. Once homogeneity of the suspension was ensured, the pH was measured ( $\mathrm{pH}$ around 7.2) and the flask was kept closed for 10 days for nanocrystalline apatite maturation. After this period the suspension was filtered in a Büchner funnel and washed with $5000 \mathrm{~mL}$ of deionized water. Then the gel was frozen in liquid nitrogen $\left(-196{ }^{\circ} \mathrm{C}\right)$ and freeze-dried to get the final apatite powder. Then the latter was stored in a freezer to prevent further maturation of the apatite nanocrystals.

Non-stoichiometric nanocrystalline carbonated apatite was chosen as mineral filler for the studied scaffolds due to its analogy of composition and structure with bone mineral and its related higher bioactivity compared with stoichiometric hydroxyapatite. In addition, the use of nanocrystalline carbonated apatite matured 10 days is based on the choice of introducing highly bioactive and biomimetic apatite filler which would be enough stable during the processing of the composite scaffolds.

\subsection{Preparation of the porous composite scaffolds}

The PLGA-apatite scaffolds were prepared by freeze casting using DMC as a solvent for PLGA (PURASORB PLGA 82/18, Purac) and different apatite/PLGA weight ratios (Table 1). PLGA was dissolved in DMC to obtain a solution at $3.5 \mathrm{wt} \%$. Then, the appropriate amount of filler (apatite) was added to the PLGA solution and homogenized by vortex and sonication $(10 \mathrm{~min})$. The suspensions were then poured into teflon molds (internal diameter: $2 \mathrm{~cm}$, height: $2 \mathrm{~cm}$ ). In order to freeze the PLGA-apatite suspensions and generate DMC crystals, the closed molds were placed in a freezer at $-20{ }^{\circ} \mathrm{C}$ for $5 \mathrm{~h}$. Molds were then opened and the frozen suspensions lyophilized (Christ Alpha 1/2-4) for $24 \mathrm{~h}\left(-55^{\circ} \mathrm{C}, 1 \mathrm{mbar}\right)$.

Table 1

PLGA/apatite weight \% ratio in composite scaffolds.

\begin{tabular}{llllll}
\hline Sample & S0 & S20 & S40 & S60 & S80 \\
\hline PLGA/apatite (wt\%) & $100 / 0$ & $80 / 20$ & $60 / 40$ & $40 / 60$ & $20 / 80$ \\
\hline
\end{tabular}

\subsection{Characterization of the apatite filler and porous composite materials}

\subsection{1. $X$ ray diffraction $(X R D)$ analysis}

The synthesized apatite was analyzed by XRD using a CPS 120 INEL diffractometer with a Co anticathode ( $\lambda_{\text {Co }}=1.7903 \AA$ ). The XRD diagram of the as-synthesized apatite was compared with the International Centre for Diffraction Data (ICDD) PDF no. 9-0432 XRD reference data for hydroxyapatite (for indexing the diffraction peaks).

\subsubsection{Fourier transformed infrared (FTIR) spectroscopy}

FTIR analyses were performed in transmission mode using a Nicolet 5700 spectrometer, in the wavenumber range $400-4000 \mathrm{~cm}^{-1}(64$ scans, resolution $4 \mathrm{~cm}^{-1}$ ). Briefly, the $\mathrm{KBr}$ pellet was prepared with a mixture of $1 \mathrm{mg}$ of the synthesized apatite and $100 \mathrm{mg}$ of $\mathrm{KBr}$ pressed at 8 tons pressure.

\subsubsection{Chemical analyses}

Calcium concentration was determined by atomic absorption spectrometry (ContrAA 300, Analytik Jena) and the phosphorus concentration by visible spectrophotometry (Shimadzu UV-1800) of the phospho-vanado-molybdenum complex at $\lambda=460 \mathrm{~nm}$. The carbonate content of the synthesized apatite was determined using a $\mathrm{CO}_{2}$ coulometer (UIC Inc., USA). All these chemical analyses were performed in duplicate or triplicate.

\subsubsection{Granulometry}

The particle size distribution of the apatite powders was measured by laser granulometry using a Malvern Mastersizer 2000 equipped with a Scirocco 2000 dry powder feeder at 2 bars pressure.

\subsubsection{Scanning electron microscope (SEM) analysis}

The morphology of apatite particles and scaffolds cross-sections was observed using a field emission gun-scanning electron microscope (FEG-SEM, FEI, model Inspect F50). Gold was sputtered onto the samples to avoid surface charging. Electron micrographs were taken using the secondary electron mode.

\subsection{6. $\mu C T$ analysis}

X-ray computed microtomography images were obtained to evaluate the three-dimensional morphology of the scaffolds. A Phoenix/GE Nanotom 180 instrument using a tungsten target was used at a voltage of $90 \mathrm{kV}$ and a current of $100 \mathrm{~mA}$, a binning of $1 \times 1$ and a time of $1000 \mathrm{~ms}$. Datosx software was used to process the data and reconstruct 3D images of the scaffolds. Images were treated using the Vg StudioMax 2.1 software. The maximum voxel size is $9 \mu \mathrm{m}$ (section uCT analysis).

\subsubsection{Mercury porosity measurements}

The porosity of the scaffolds was measured using a mercury intrusion porosimeter (AutoPore III, Micromeritics Instruments Inc., Norcross, GA), which allows detection of pores in the range $600-0.003 \mu \mathrm{m}$. The total percentage porosity was calculated by:

$\mathrm{P}_{\text {tot }}=\mathrm{d}_{\mathrm{app}} \cdot \mathrm{V}_{\mathrm{Hg}} \times 100$

where $d_{a p p}$ is the apparent density of the scaffold and $V_{H g}$ is the total mercury intrusion volume per gram of specimen analyzed. The pore size distribution was calculated as the differential mercury intrusion volume plotted versus the pore size.

\subsubsection{Compression tests}

Compression tests were carried out on cylindrical PLGA-apatite porous scaffolds (height $\sim 16 \mathrm{~mm}$, diameter $\sim 20 \mathrm{~mm}$ ) using an MTS tension compression machine equipped with a $2 \mathrm{kN}$ load cell. The displacement was imposed at $0.02 \mathrm{~mm} / \mathrm{s}$. A preload of $2 \mathrm{~N}$ was performed in order to obtain a smooth surface on the scaffold and to limit the effect of surface irregularity due to molding. The sample was then unloaded 
down to $1 \mathrm{~N}$ compression; its height was then the initial data of the compression test carried out up to $10 \mathrm{~N}$. Measurements were achieved in triplicate. Some samples were compressed down to $50 \mathrm{~N}$ in order to identify possible scaffold failures.

\subsubsection{In vitro degradation tests}

The composite scaffolds were incubated at $37^{\circ} \mathrm{C}$ in $300 \mathrm{~mL}$ of TRIS solution at $\mathrm{pH}$ 7.4. The samples were placed in a porous vial to ensure the scaffold was submersed into the buffer solution, with agitation of $100 \mathrm{rpm}$. At scheduled times ( 14 and 28 days) scaffold samples were removed from the TRIS solution and weighed, washed with deionized water and dried for $48 \mathrm{~h}$ at room temperature. After this period of drying, the samples were weighed again. This study was performed on scaffolds S40 and S60, as well as on S0 as the control material. This test allowed characterization of the water uptake, PLGA molecular weight and weight loss of the scaffold. All the tests were conducted in triplicate.

Water uptake was calculated as follows:

water uptake $=\left(\mathrm{w}_{\mathrm{t}}-\mathrm{w}_{0}\right) / \mathrm{w}_{\mathrm{t}} \times 100$

where $w_{t}$ is the scaffold weight while wet at time $t$, and $w_{0}$ is the weight of the dried scaffold after the degradation test.

Weight loss was calculated as follows:

weight loss $(\%)=\left(\mathrm{w}_{\mathrm{i}}-\mathrm{w}_{0}\right) / \mathrm{w}_{\mathrm{i}} \times 100$

where $\mathrm{w}_{\mathrm{i}}$ is the initial weight of the scaffold and $\mathrm{w}_{0}$ is the weight of the dried sample after the degradation test.

\subsubsection{Gel permeation chromatography}

The variation in the average molecular weight (Mw) of the polymer (PLGA) was monitored by gel permeation chromatography during the in vitro degradation process. The scaffolds were solubilized in tetrahydrofuran (THF) at a concentration of $15 \mathrm{mg} / \mathrm{mL}$ before injection in an isocratic HPLC chromatograph pump-1515 using a Waters Instruments 2412 refractive index detector.

\section{Results}

\subsection{Apatite filler}

The XRD pattern and FTIR spectrum of the synthesized apatite are presented in Fig. 1. A strong broadening of diffraction lines can be observed as compared with reference XRD data corresponding to well-crystallized stoichiometric hydroxyapatite (Fig. 1a) testifying to the poor crystallinity of the synthesized apatite. In addition we can see that this synthesized nanocrystalline apatite is analogous to bone apatite (as compared with apatite of 18 months rat bone, Fig. 1a). The FTIR spectrum of the synthesized apatite is presented in Fig. 1b: the phosphate, carbonate and water molecule characteristic bands are clearly visible, indicating and confirming that the synthesized nanocrystalline apatite is a carbonated apatite analogous to bone mineral.

Considering the calcium (31.25 wt\%), phosphorus (13.51 wt\%) and carbonate (3.9 wt\%) titration results, the $\mathrm{Ca} / \mathrm{P}$ and $\mathrm{Ca} /(\mathrm{P}+\mathrm{C})$ atomic ratios of the synthesized apatite were calculated: 1.79 and 1.56 , respectively. They both testify to the non-stoichiometry and carbonation of the prepared apatite.

The particle size distribution of the synthesized apatite is presented as supporting information in Fig. SM1 (Supplementary material). The monomodal curve shows that the apatite powder is constituted of small aggregates (mean diameter $4.47 \mu \mathrm{m}$ ) of apatite nanocrystals due to the freeze-drying process (apatite gel frozen at $-196{ }^{\circ} \mathrm{C}$ before freeze-drying).
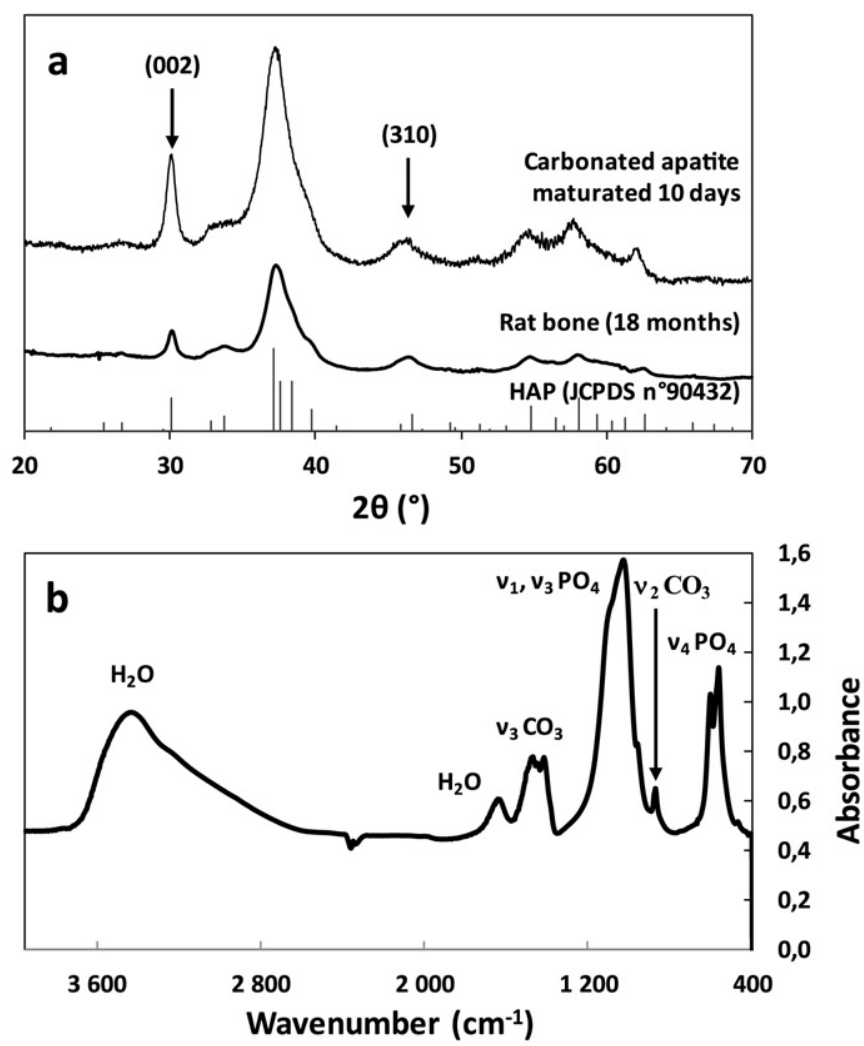

Fig. 1. Characterization of the synthesized carbonated apatite: a) X-ray diffraction pattern of the synthesized apatite compared with rat bone and stoichiometric hydroxyapatite (HAP) reference data, b) FTIR spectrum of the synthesized apatite.

\subsection{Composite scaffolds}

Five types of samples were prepared with different apatite filler ratios (wt\%) in PLGA-apatite composites (Table 1). Samples presented different macroscopic appearance (Fig. 2) depending on the initial apatite filler ratio in PLGA-apatite suspension. S0, S20, S40 and S60 were monoliths around $1.6 \mathrm{~cm}$ high and with a diameter of $2 \mathrm{~cm}$. No significant shrinkage was observed for these samples. Domains with different porosity orientation can be observed in the lateral view of the S20 scaffold (Fig. 2c), less distinguishable in its top view (Fig. 2a). The porosity seemed tubular and aligned within these macro-domains but the domains themselves had an isotropic orientation. We also observed such architecture for S40 and S60 scaffolds (data not shown). Contrarily to the other types of scaffold, the S80 sample was fragile and friable and looked like a powder (Fig. 2d). This sample characteristic can be explained by the presence of a very high amount of apatite particles and thus of the lowest PLGA rate which does not allow enough cohesion to be maintained between apatite particles in such composite materials. No further study was been performed on the S80 sample.

These macroscopic observations were completed by microtomography measurements for samples S0 and S40 with two volume analyzes: large views, $10 \times 4 \times 3 \mathrm{~mm}$ (Fig. $3 \mathrm{a}$ and b) and focused views, $3 \times 3 \times 3 \mathrm{~mm}$ (Fig. $3 \mathrm{c}$ and d). Different electronic densities allowed discrimination of the polymer matrix, the apatite filler (depending on the particle size) and the porosity (air). Sample S0 (without apatite filler) displayed a structure made up of large and layered parallel plates, spaced from 50 to $500 \mu \mathrm{m}$ apart, aligned along different domains (probably depending on the heat transfer direction) and connected by struts. The porosity of S40 seemed less organized even if the pore anisotropy was still visible, with a smaller diameter than for S0. These 3D analyses also demonstrated that apatite fillers (brilliant points) were uniformly distributed at the scale of the scaffold and that there was no gradient or separation of the composite constituents. 


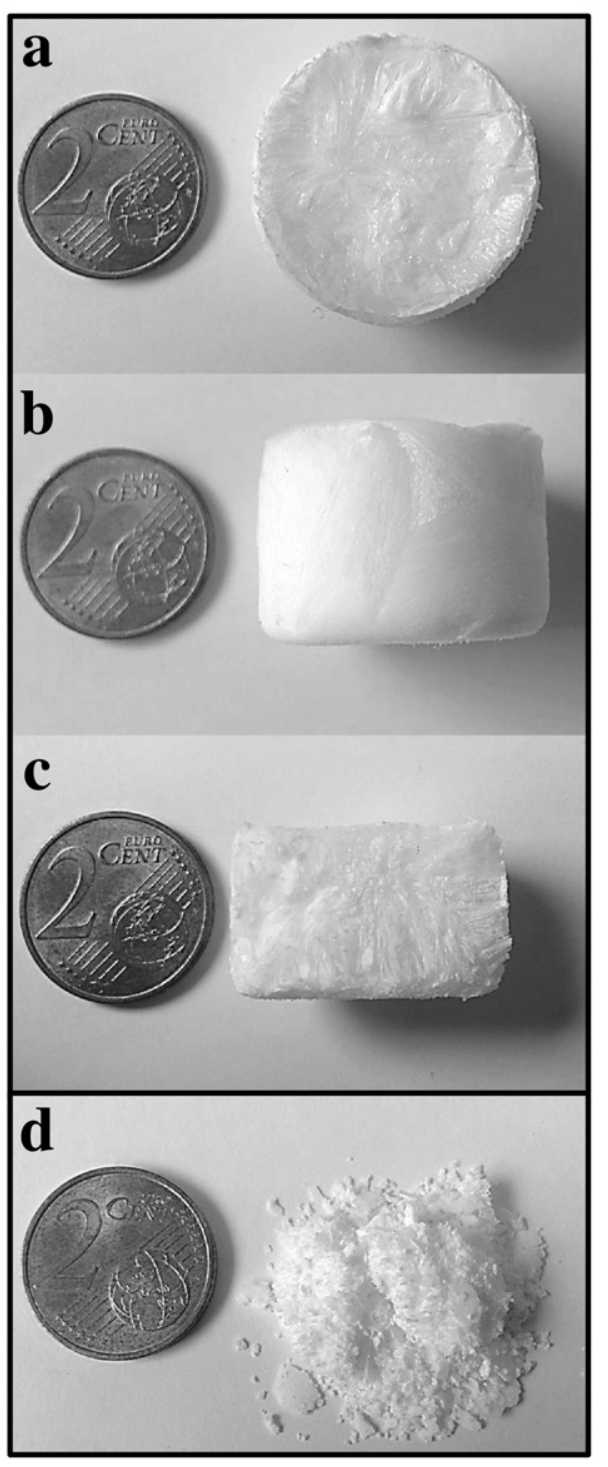

Fig. 2. Optical images of PLGA-apatite scaffolds: S20 (a-top view, b-lateral view, clongitudinal cross section) and S80 samples (d).

FEG-SEM characterization (Fig. 4) was carried on samples S0, S20, S40 and S60 at different magnifications $(\times 100, \times 500, \times 10,000)$ after they were frozen in liquid nitrogen and broken to observe the internal organization. At the lower magnification (Fig. 4a, d, g, j) all the samples except SO exhibited principal lamellar porosity for which the cross-section was between 150 and $300 \mu \mathrm{m}$ width and between $600 \mu \mathrm{m}$ and $1 \mathrm{~mm}$ long. For S0, the structure seemed to collapse, contrary to what was observed by $\mu \mathrm{CT}$. For all the samples, smaller tubular porosity between 30 and $70 \mu \mathrm{m}$ was embedded in the principal one (Fig. 4b, e, h, k). Finally, micrometer-size porosity (pores with a diameter of a few microns) was present in the walls of S40 and S60. At higher magnification (Fig. 4c, f, i, 1), it could be observed that the roughness of the walls was increased because of the higher amounts of apatite filler from S0 to S60. For S20, the apatite particles were mainly inside the walls (Fig. 4f) while they appeared more numerous at the surface up to S60 (Fig. 41). For this latter sample we could observe that the walls of the pores were covered by homogeneously distributed apatite particle aggregates.

Mercury porosimetry was performed to quantitatively assess the volume and pore size distribution of scaffolds as a function of the apatite filler ratio (Table 2 and Fig. 5). Porosity of around 63\% was observed for all the samples except for S0 which presented a higher porosity $(\sim 72 \%)$ when compared to S20, S40 and S60, suggesting a small decrease in porosity when apatite particles are introduced into the scaffolds.

The pore size distribution was also determined by measuring the amount of mercury introduced into the sample as a function of the applied pressure (pore diameter is related to intrusion pressure). Corresponding curves are presented in Fig. 5. For the S0 sample, three main peaks respectively centered around 380, 160 and $60 \mu \mathrm{m}$ can be observed, which is consistent with the SEM micrographs (Fig. 4). For the other samples (S20, S40 and S60 composite scaffolds), the introduction of apatite particles induced a decrease in porosity related to pores of around $60 \mu \mathrm{m}$ with a widening of the distribution of pore sizes. Two pore diameters remained present: one centered around $160 \mu \mathrm{m}$ and the other around $380 \mu \mathrm{m}$.

\subsection{Scaffold properties}

In order to evaluate the effect of the apatite filler ratio on the mechanical properties of the PLGA-apatite porous scaffolds, uniaxial mechanical compression studies were performed and are presented in Fig. 6. Tests reproducibility was good, as illustrated in Fig. SM2 (Supplementary material). The mechanical behavior exhibited by the prepared scaffolds revealed two main regimes. The first one was a linear elastic regime. Young's elastic modulus was calculated at this stage (based on three tests) for all samples (Fig. 7). When comparing this first part of the curve for all the samples, we can see that the Young's modulus increased from 0.16 (S0) to $0.34 \mathrm{MPa}(\mathrm{S} 40)$. Then, after having reached a maximum for $40 \%$ apatite filler, it decreased for S60. Considering again the uniaxial stress-strain curves (Fig. 6), the second step corresponded to a plastic regime of the scaffold. For a similar compressive stress, the elongation decreased from S0 to S40 (minimal elongation) and then increased for S60.

An in vitro degradation test was performed in order to evaluate the influence of the apatite filler rate on the degradation behavior of PLGA and PLGA-apatite porous scaffolds. Fig. 8a shows the aqueous solution uptake by the different scaffolds prepared. The scaffolds with higher apatite content exhibited a higher capacity to absorb TRIS buffer solution during the first 14 days of the degradation test. Then, for a longer period (28 days), no significant difference between the three scaffolds was observed. Fig. $8 \mathrm{~b}$ shows the dry material mass (expressed in wt\%) for each type of scaffold after 14 and 28 days of degradation test. A weight loss between 2 and 4 weeks for all scaffolds, except for S0 (without apatite filler), could be observed. For this scaffold, there was a weight gain during the first period of the degradation test and this gain was then enhanced after 28 days of degradation. This effect is most probably due to polymer and thus composite swelling that typically occurs during the hydrolytic degradation of the polyester [26]. The weight loss in the composite scaffolds can be correlated to the apatite filler ratio in the scaffolds.

The evolution of the Mw of the PLGA in PLGA and PLGA-apatite scaffolds is presented in Fig. 8c. We can see that the Mw decreased substantially between 14 and 28 days of degradation for all the porous composite samples tested. The S0 scaffold (without apatite filler) showed the lowest Mw after 28 days of degradation; these results point out the buffering role of the apatite filler in the control of autocatalytic hydrolysis/degradation of PLGA materials.

\section{Discussion}

\subsection{Scaffold architecture}

The fact that no significant macroscopic shrinkage was observed is the first interesting property of these PLGA-apatite scaffolds. Indeed, the use of DMC as a solvent allows avoidance of shrinkage contrarily to other solvents used for PLGA freeze-casting (ethylene carbonate, dimethyl sulfoxide, 1,4-dioxane) for which conic shrinkage can be $30 \%$ higher [26]. This is particularly suitable for molding processability. 

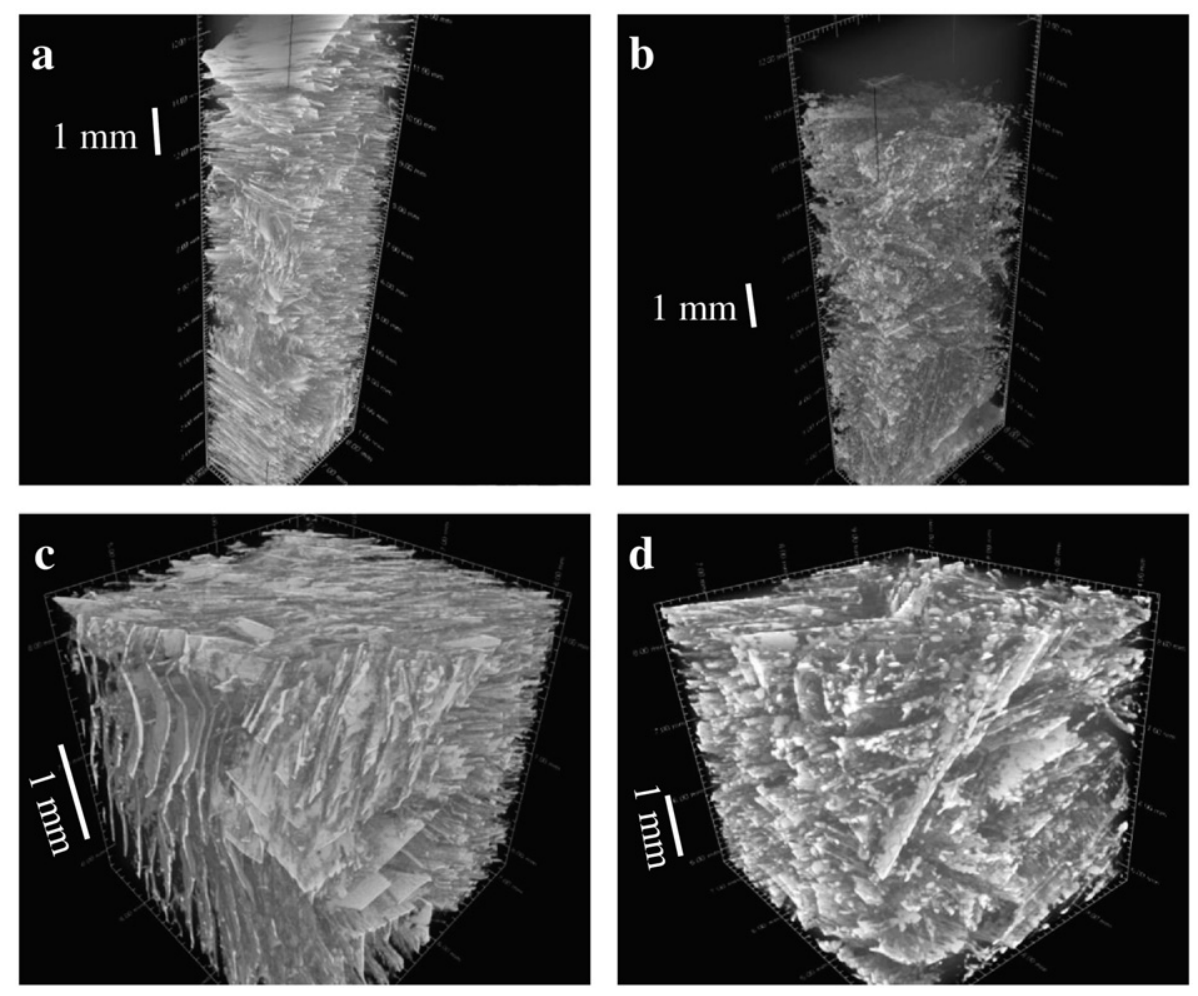

Fig. 3. $\mu \mathrm{CT}$ images of PLGA scaffold SO (a, c) and PLGA-apatite scaffold S40 (b, d): total height in the center of the scaffold (a, b) and zoom within this region (c, d).

Considering macroscopic observations, $\mu \mathrm{CT}$ analyses, SEM observations and mercury porosimetry measurements, porosity was homogeneous within the prepared scaffolds and ordered in sheets within macro-domains, the domains themselves having an isotropic orientation. This can be explained by the fact that no preferential orientation was followed by the growing DMC crystals at the sample scale because the freeze-casting was carried out in a Teflon mold, i.e. in a thermal isolating material. This is a key parameter to get isotropic mechanical properties for small bone defect filling. The structure of this large macroporosity was composed of layered parallel plates for most the samples (S20, S40, S60). Indeed, due to the planar structure of the DMC molecule [27], DMC preferentially forms planar, rather than dendritic, crystals [26]. Surprisingly, the porosity structure observed on $\mu \mathrm{CT}$ images and SEM cross-section micrographs appeared different (organized lamellar porosity versus poorly-organized porosity) for the S0 porous scaffold. This could be attributed to a collapse during sectioning of the samples for SEM preparation related to decreased rigidity of the sample without apatite filler (see part Section 4.2) (lower Young's modulus of the walls).

Beyond the main and structuring macroporosity of several hundreds of microns (S0), two hierarchical and smaller porosities could also be observed using SEM and mercury intrusion analyses, which depended on the type of scaffold: several tens of microns (Fig. 3) for all the samples and a few microns (Fig. 4, within the walls) for S40 and S60. According to Pawelec et al. [28], the first bimodal distribution (S0 and S20) could be attributed to primary and secondary nucleation of DMC crystals. Indeed, secondary nucleation occurs in particular for a low cooling rate. It is the case for these scaffolds because the freezing was carried out in a Teflon mold and with an external temperature of $-20{ }^{\circ} \mathrm{C}$ (low cooling rate compared to a metal mold/interface associated to liquid nitrogen). For scaffolds containing apatite filler, each apatite particle or agglomerate could serve as a nucleating site, enhancing the secondary nucleation and then resulting in the microporosity seen in the walls. After the crystal growth step, the resulting DMC crystals reached various sizes which resulted in larger pore size distribution.
From a biological point of view, S40 and S60 PLGA-apatite scaffolds appear to be the most suitable samples because they combine large and interconnected macroporosity allowing potential cell colonization and angiogenesis with micron-scale porosity within the walls which has been considered to allow adsorption of (bio)molecules [29].

3D $\mu \mathrm{CT}$ analyses also demonstrated that apatite particles were uniformly distributed at the scaffold scale and that there were no preferential zones or gradient from the top to the bottom due to gravity. As summed up by Supova [30], the dispersion of apatite in polymeric matrices and control of inorganic and organic phase mixing is a critical challenge in the design of such systems. This result demonstrates that the preparation process leads to good dispersion. This homogeneity was also present at the wall scale for S40 and S60 scaffolds. Indeed, for these samples the walls of the pores were covered by homogeneously distributed aggregates of apatite particles with diameters of a few microns, similar to the initial apatite powder (Fig. SM1). The resulting wall roughness and the presence of carbonated apatite both in the bulk and at the material surface is expected to enhance the hydrophilicity compared to neat PLGA and to promote osteogenic cell adhesion and differentiation, leading to bone ingrowth [31].

\subsection{Scaffold mechanical properties}

For mechanical properties, considering the stress-strain curves of all prepared scaffolds (Fig. 6) and according to the Gibson and Ashby model [32], several regimes could be observed. The first one was an elastic regime. The slopes of these stress-strain curves correspond to an effective Young's modulus. The measured values increased from $0.16 \mathrm{MPa}$ (S0) to $0.34 \mathrm{MPa}$ (S40). As this step is due to cell edge bending or face stretching, this behavior is in good agreement with the literature: there was an increasing trend in composite rigidity compared to the polymer due to the decrease of polymer segment mobility blocked by inorganic apatite particles. Boccaccini et al. [33] demonstrated it with PLGA/Bioglass ${ }^{\circledR}$ composite scaffolds. In our study, it is interesting to note that the rigidity of the walls was improved up to the $40 \%$ apatite filler rate which is a major property for biomedical applications. The 

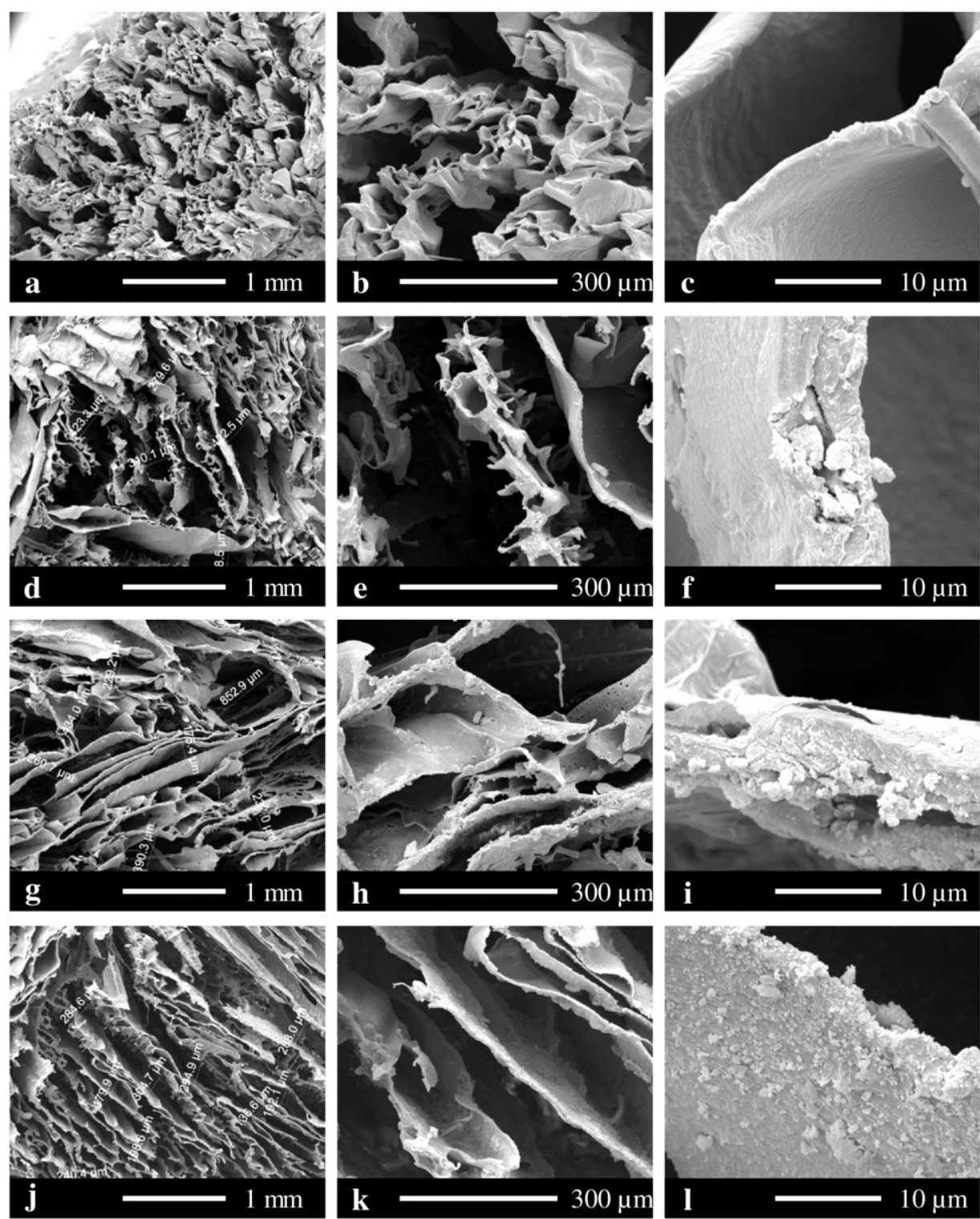

Fig. 4. SEM micrographs of PLGA and PLGA-apatite scaffolds at different magnifications: S0 (a, b, c), S20 (d, e, f), S40 (g, h, i), S60 (j, k, l).

decrease of the Young's modulus for the $\mathrm{S} 60$ scaffold could be related to the agglomeration of apatite particles. Indeed, it has been demonstrated that well-dispersed nanoceramics in PLGA enhance the tensile modulus, tensile strength at yield, ultimate tensile strength and compressive modulus similar to those obtained in more agglomerated nanoceramics in PLGA [34]. The high amount of apatite filler in the S60 scaffold must lead to more agglomerate apatite particles and, as a consequence a less efficient composite in terms of mechanical properties.

According to Gibson [32], the second stage of the stress-strain curves corresponds to a stress plateau. During this plateau, cells gradually collapse by elastic buckling, plastic yielding or brittle crushing. Then, a third step corresponding to the material densification is generally observed for porous materials although it was not observed in the present study.

Table 2

Total porosity (\%) of the prepared PLGA and PLGA-apatite composite scaffolds.

\begin{tabular}{lllll}
\hline Sample & S0 & S20 & S40 & S60 \\
\hline Porosity (\%) & 72.1 & 62.8 & 62.9 & 63.9 \\
\hline
\end{tabular}

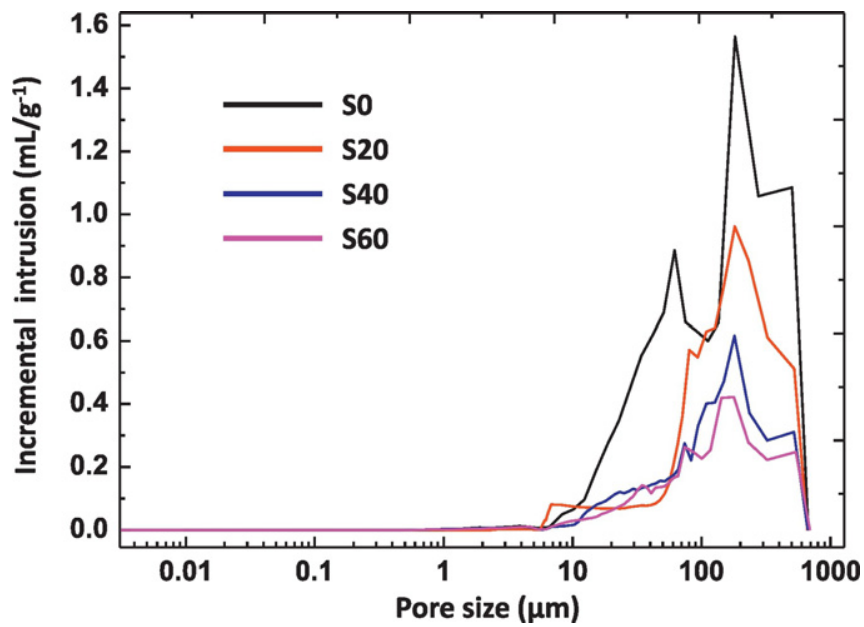

Fig. 5. Pore size distribution measured by mercury intrusion for PLGA and PLGA-apatite scaffolds: S0, S20, S40 and S60. 


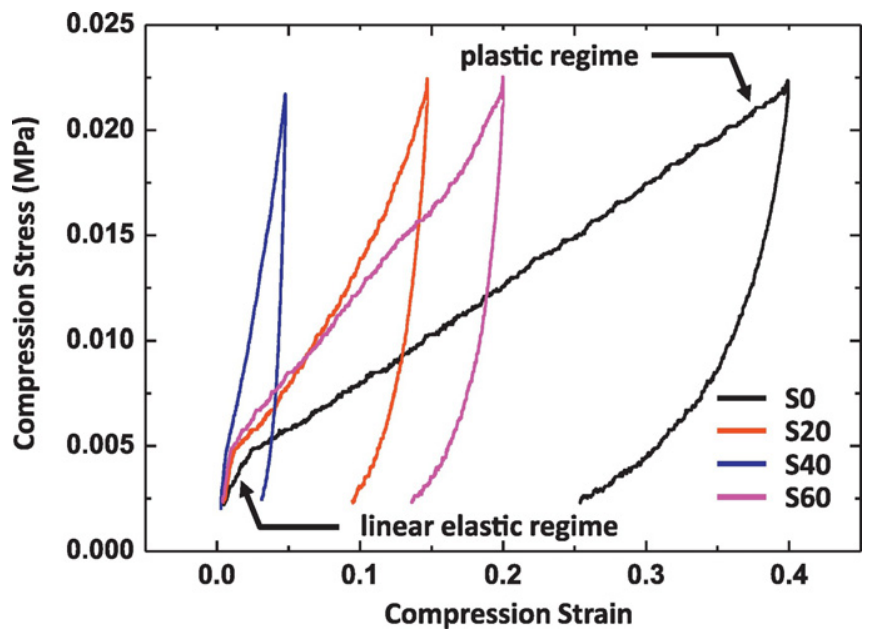

Fig. 6. Uniaxial stress-strain curves for PLGA and PLGA-apatite scaffolds: S0, S20, S40 and S60.

Even if the scaffold porosity described in this study is two-dimensional and anisotropic (at the microdomain scale), two-dimensional cellular solid micromechanical models (honeycomb) are not totally adapted to the tested samples because several cell sizes and orientations were variable (several porous domains coexisted with their own orientation). It could explain why the two last steps were mixed for the present scaffolds. Indeed, as the compression was uniaxial and the porosity domains aligned in random directions, buckling, collapse and densification could occur at the same time depending on the domain. The fact that, for a similar compressive stress, the elongation decreased from S0 to S40 (minimal elongation) and then increased for S60 could be linked to: i) the presence of enough apatite particles to block chain mobility and then delayed buckling when the applied strength was improved (S0 $\rightarrow \mathrm{S} 40$ ), ii) when the apatite particles were present in very high amounts compared to the PLGA matrix, bigger agglomerates and induced microporosity could lead to a transfer from a buckling mechanism to brittle crushing.

\subsection{Degradation tests}

The scaffolds containing the highest amount of apatite showed a greater aqueous solution uptake than the control scaffold (S0). This can be attributed to the larger surface area covered with apatite particles, generating a micro/nanostructure with more hydrophilic properties on the surface of the scaffolds and additional microporosity.

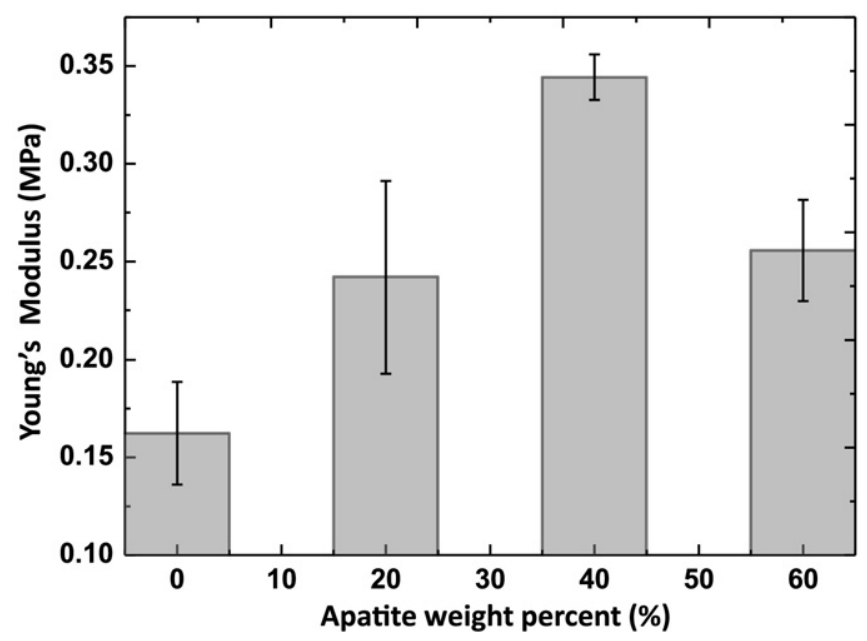

Fig. 7. Evolution of Young's modulus with the apatite filler rate (wt\%) in the scaffolds.
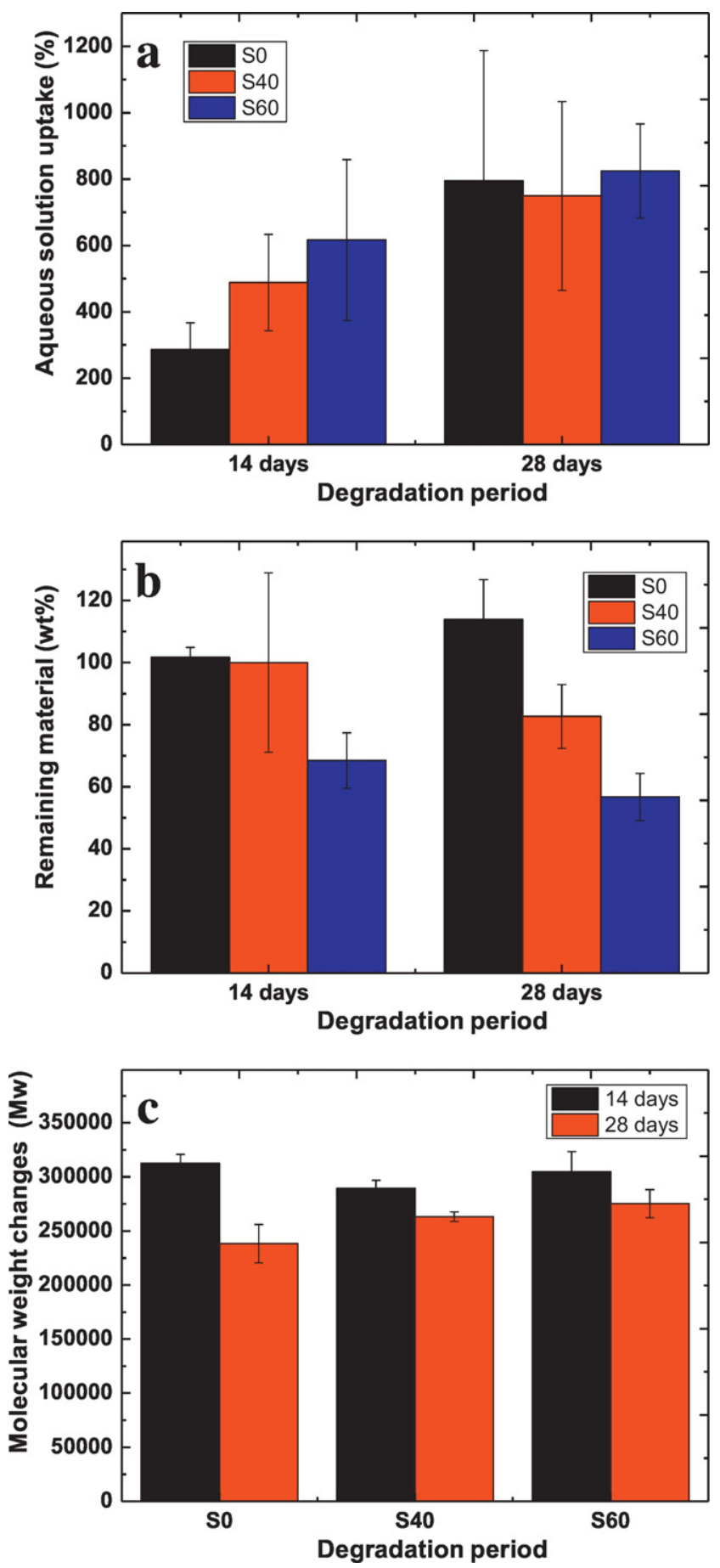

Fig. 8. Evolution of aqueous solution uptake (a), remaining material (wt\%) (b) and PLGA molecular weight (c) during in vitro degradation test of S0, S40 and S60 scaffolds.

Moreover, the associated microporosity allows a higher uptake. The hydrophilicity of scaffolds has a great influence on material performance in a biological environment, as demonstrated by Idaszek et al. [35]. The more hydrophilic scaffolds, which have a higher contact area with the solution, suffered weight loss in a proportional rate to the absorbed amount of Tris solution. Furthermore, part of the weight loss of the scaffolds containing apatite is due to disintegration, dissolution and erosion of the particles located on the surface of the scaffolds. We have also to consider that the solubility product of carbonated apatites $(2.88$ $10^{-112} \mathrm{~mol}^{18} \mathrm{~L}^{-18}$ ) is significantly greater than that of HAP (5.52 $10^{-118} \mathrm{~mol}^{18} \mathrm{~L}^{-18}$ ) [36]. Therefore, the weight loss exhibited by the scaffolds containing inorganic carbonated apatite particles is not 
necessarily directly proportional to polymer degradation (higher specific area associated to additional microporosity). This is corroborated by the GPC results that showed scaffold S0 with the lowest Mw after 28 days of degradation. This may be due to autocatalytic acidic degradation suffered by PLGA due to the release of lactic and glycolic acids; in apatite-containing scaffolds the presence of carbonated apatite particles has a buffering role and limits acidification due to PLGA hydrolysis which leads to dissolution of apatite but limits the PLGA autocatalytic degradation process [37].

\section{Conclusion}

This study demonstrated the feasibility of porous PLGA-biomimetic apatite composite scaffolds preparation by freeze-casting using DMC as a solvent, leading to a material without any significant shrinkage. The composite scaffold porosity was homogeneously distributed, mainly two-dimensional and related to anisotropic macro-domains. Three main macropore sizes were identified for the prepared PLGA-apatite scaffolds: they were centered around $60 \mu \mathrm{m}, 160 \mu \mathrm{m}$ and $380 \mu \mathrm{m}$.

We pointed out the determinant role of apatite ratio within the composite scaffold in terms of material cohesion, mechanical properties and in vitro degradation properties. The apatite filler ratio limit to obtain a monolithic porous scaffold was $60 \mathrm{wt} \%$. An increase of the porous scaffold Young's modulus was observed up to $40 \mathrm{wt} \%$ of apatite filler ratio whereas in this range of filling ratio the plasticity of the scaffold was decreased, indicating that there is an optimum biomimetic apatite ratio to combine good mechanical properties and material cohesion. Interestingly, the rigidity of pore walls was improved in the presence of biomimetic apatite particles, which is a major property for bone engineering applications: it should prevent the collapse of porosity during cutting of the samples by surgeons to fill and/or repair small bone defects.

The in vitro degradation study showed that higher apatite filler ratios limited PLGA degradation (less decrease in Mw) in aqueous medium especially after 4 weeks of degradation test and enhanced the hydrophilicity of the scaffolds (higher aqueous solution uptake) which is expected to improve the biological properties of the scaffolds in addition to the bioactivity related to the presence of the apatite analogous to bone mineral.

\section{Acknowledgements}

The authors thank the Coordenação de Aperfeiçoamento de Pessoal de Nível Superior (CAPES) (886), a foundation of the ministry of education in Brazil, for the financial support of part of this research work (one-year doctoral CAPES fellowship for Mariane Giacomini Schardosim). The French FERMaT Midi-Pyrénées Federation FR3089 is acknowledged for providing X-ray tomography laboratory facility.

\section{Appendix A. Supplementary data}

Supplementary data to this article can be found online at http://dx. doi.org/10.1016/j.msec.2017.03.302.

\section{References}

[1] M.V. Belthur, J.D. Conway, G. Jindal, A. Ranade, J.E. Herzenberg, Bone graft harvest using a new intramedullary system, Clin. Orthop. Relat. Res. 466 (2008) 2973-2980.

[2] D.H. Kim, R. Rhim, L. Li, J. Martha, B.H. Swaim, R.J. Banco, et al., Prospective study of iliac crest bone graft harvest site pain and morbidity, Spine J. 9 (2009) 886-892.

[3] T. Schouman, M. Schmitt, C. Adam, G. Dubois, P. Rouch, Influence of the overall stiffness of a load-bearing porous titanium implant on bone ingrowth in critical-size mandibular bone defects in sheep, J. Mech. Behav. Biomed. Mater. 59 (2016) 484-496.

[4] K. Rezwan, Q.Z. Chen, J.J. Blaker, A.R. Boccaccini, Biodegradable and bioactive porous polymer/inorganic composite scaffolds for bone tissue engineering, Biomaterials 27 (2006) 3413-3431.

[5] P.V. Giannoudis, H. Dinopoulos, E. Tsiridis, Bone substitutes: an update, Injury 36 (2005) S20-S27.

[6] T. Matsuno, K. Omata, Y. Hashimoto, Y. Tabata, T. Satoh, Alveolar bone tissue engineering using composite scaffolds for drug delivery, Jpn. Dent. Sci. Rev. 46 (2010) 188-192.
[7] D. Eichert, C. Drouet, H. Sfihi, C. Rey, C. Combes, Nanocrystalline apatite-based biomaterials: synthesis, processing and characterization, in: J.B. Kendall (Ed.), Biomaterials Research Advances, Nova Science Publishers 2007, pp. 93-143.

[8] C. Rey, C. Combes, C. Drouet, S. Cazalbou, D. Grossin, F. Brouillet, et al., Surface properties of biomimetic nanocrystalline apatites; applications in biomaterials, Prog. Cryst. Growth Charact. Mater. 60 (2014) 63-73.

[9] D. Tadic, F. Beckmann, K. Schwarz, M. Epple, A novel method to produce hydroxyapatite objects with interconnecting porosity that avoids sintering, Biomaterials 25 (2004) 3335-3340

[10] E. Meurice, F. Bouchart, J.C. Hornez, A. Leriche, D. Hautcoeur, V. Lardot, et al., Osteoblastic cells colonization inside beta-TCP macroporous structures obtained by icetemplating, J. Eur. Ceram. Soc. 36 (2016) 2895-2901.

[11] W.J.E.M. Habraken, J.G.C. Wolke, J.A. Jansen, Ceramic composites as matrices and scaffolds for drug delivery in tissue engineering, Adv. Drug Deliv. Rev. 59 (2007) 234-248.

[12] C.C. Zhou, X.J. Ye, Y.J. Fan, F.Z. Qing, H.J. Chen, X.D. Zhang, Synthesis and characterization of cap/col composite scaffolds for load-bearing bone tissue engineering, Compos. Part B 62 (2014) 242-248.

[13] X. Chen, Y. Liu, J. Yang, W. Wu, L. Miao, Y. Yu, et al., The synthesis of hydroxyapatite with different crystallinities by controlling the concentration of recombinant CEMP1 for biological application, Mater. Sci. Eng. C 59 (2016) 384-389.

[14] A.R. Boccaccini, V. Maquet, Bioresorbable and bioactive polymer/Bioglass ${ }^{\circledR}$ composites with tailored pore structure for tissue engineering applications, Compos. Sci. Technol. 63 (2003) 2417-2429.

[15] D. Velasco, L. Benito, M. Fernández-Gutiérrez, J. San Román, C. Elvira, Preparation in supercritical $\mathrm{CO}_{2}$ of porous poly(methyl methacrylate)-poly(l-lactic acid) (PMMAPLA) scaffolds incorporating ibuprofen, J. Supercrit. Fluids 54 (2010) 335-341.

[16] W. Zhao, J. Li, K. Jin, W. Liu, X. Qiu, C. Li, Fabrication of functional PLGA-based electrospun scaffolds and their applications in biomedical engineering, Mater. Sci. Eng. C 59 (2016) 1181-1194.

[17] A.R. Boccaccini, J.J. Blaker, V. Maquet, R.M. Day, R. Jérôme, Preparation and characterisation of poly(lactide-co-glycolide) (PLGA) and PLGA/Bioglass ${ }^{\circledR}$ composite tubular foam scaffolds for tissue engineering applications, Mater. Sci. Eng. C 25 (2005) 23-31.

[18] Z. Fereshteh, P. Nooeaid, M. Fathi, A. Bagri, A.R. Boccaccini, The effect of coating type on mechanical properties and controlled drug release of PCL/zein coated $45 \mathrm{~S} 5$ bioactive glass scaffolds for bone tissue engineering, Mater. Sci. Eng. C 54 (2015) 50-60

[19] J. Ziegler, U. Mayr-Wohlfart, S. Kessler, D. Breitig, K.P. Günther, Adsorption and release properties of growth factors from biodegradable implants, J. Biomed. Mater. Res. 59 (2002) 422-428.

[20] C. Liu, Z. Xia, J.T. Czernuszka, Design and development of three-dimensional scaffolds for tissue engineering, Chem. Eng. Res. Des. 85 (2007) 1051-1064.

[21] Q. Tan, S. Li, J. Ren, C. Chen, Fabrication of porous scaffolds with a controllable microstructure and mechanical properties by porogen fusion technique, Int. J. Mol. Sci. 12 (2011) 890-904.

[22] H. Zhang, A.I. Cooper, Synthesis and applications of emulsion-templated porous materials, Soft Matter 1 (2005) 107-113.

[23] Y.F. Chou, J.C.Y. Dunn, B.M. Wu, In vitro response of MC3T3-E1 preosteoblasts within three-dimensional apatite-coated PLGA scaffolds, J. Biomed. Mater. Res. B Appl. Biomater. 75 (2005) 81-90

[24] J. Guo, Z. Xu, Y. Liu, X. Wang, Y. Zhao, Synthesis of novel 25-hydroxyprotopanaxadio derivatives by methylation and methoxycarbonylation using dimethyl carbonate as an environment-friendly reagent and their anti-tumor evaluation, Bioorg. Med. Chem. Lett. 26 (2016) 4763-4768.

[25] Y. Cao, T.I. Croll, A.J. Oconnor, G.W. Stevens, J.J. Cooper-White, Systematic selection of solvents for the fabrication of 3D combined macro- and microporous polymeric scaffolds for soft tissue engineering. J. Biomater. Sci. Polym. Ed. 17 (2006) 369-402.

[26] M. Navarro, M.P. Ginebra, J.A. Planell, C.C. Barrias, M.A. Barbosa, In vitro degradation behavior of a novel bioresorbable composite material based on PLA and a soluble CaP glass, Acta Biomater. 1 (2005) 411-419.

[27] H. Sun, S.J. Mumby, J.R. Maple, A.T. Hagler, Ab initio calculations on small molecule analogues of polycarbonates, J. Phys. Chem. 99 (1995) 5873-5882.

[28] K.M. Pawelec, A. Husmann, S.M. Best, R.E. Cameron, Ice-templated structures for biomedical tissue repair: from physics to final scaffolds, Appl. Phys. Rev. 1 (2014).

[29] Y.S. Pek, S. Gao, M.S.M. Arshad, K.J. Leck, J.Y. Ying, Porous collagen-apatite nanocomposite foams as bone regeneration scaffolds, Biomaterials 29 (2008) 4300-4305.

[30] M. Šupová, Problem of hydroxyapatite dispersion in polymer matrices: a review, J. Mater. Sci. Mater. Med. 20 (2009) 1201-1213.

[31] L. Pang, Y. Hu, Y. Yan, L. Liu, Z. Xiong, Y. Wei, et al., Surface modification of PLGA/ßTCP scaffold for bone tissue engineering: hybridization with collagen and apatite, Surf. Coat. Technol. 201 (2007) 9549-9557.

[32] L.J. Gibson, Biomechanics of cellular solids, J. Biomech. 38 (2005) 377-399.

[33] V. Maquet, A.R. Boccaccini, L. Pravata, I. Notingher, R. Jérôme, Porous poly $(\alpha-$ hydroxyacid)/Bioglass ${ }^{\circledR}$ composite scaffolds for bone tissue engineering. I: preparation and in vitro characterisation, Biomaterials 25 (2004) 4185-4194.

[34] T.J. Webster, C. Ergun, R.H. Doremus, R.W. Siegel, R. Bizios, Specific proteins mediate enhanced osteoblast adhesion on nanophase ceramics, J. Biomed. Mater. Res. 51 (2000) 475-483.

[35] J. Idaszek, E. Kijeńska, M. Łojkowski, W. Swieszkowski, How important are scaffolds and their surface properties in regenerative medicine, Appl. Surf. Sci. 388 (2016) 762-774.

[36] R. Tang, Z.J. Henneman, G.H. Nancollas, Constant composition kinetics study of carbonated apatite dissolution, J. Cryst. Growth 249 (2003) 614-624.

[37] R. Dorati, C. Colonna, I. Genta, T. Modena, B. Conti, Effect of porogen on the physicochemical properties and degradation performance of PLGA scaffolds, Polym. Degrad. Stab. 95 (2010) 694-701. 